\title{
Sociologia do Trabalho e Mestrados Profissionais: busca de identidade e reconhecimento da profissionalidade docente
}

\section{Sociology of Work and Professional Masters: search for identity and recognition of teaching professionality}

Walter Rodrigues Marques ${ }^{1 *}$, André Nogueira Machado1 ${ }^{5}$, Mariceia Ribeiro Lima2 ${ }^{2}$, Raquel Marques Costa $3^{3}$, Francinete Braga Santos $4^{4}$, Raimunda Maria Barbosa Sá5 ${ }^{1}$, Ivameire Martins

Alves Araújo6 ${ }^{1}$, Jocenilson Mendes Costa $7^{1}$.

\begin{abstract}
RESUMO
O artigo tem como foco destacar a importância do reconhecimento da profissionalidade docente como atividade atribuída especificamente a professores e professoras, tendo em vista que a desenvolvem durante suas vidas no exercício da função. Objetiva trazer visibilidade para a profissão de professor no intuito de fazer com que a sociedade valorize o trabalho dos professores e das professoras brasileiras, refletindo sobre a importância de uma profissão que é base para todas as outras, pois é por meio do trabalho desses agentes da educação que todas as profissões se desenvolvem. Para isso, buscamos conceituar também o termo "trabalho", trazendo as contribuições da Sociologia do Trabalho e autores como Ricardo Antunes, Ricardo Ramalho, Jacob Carlos Lima e Jacques Le Goff. No concernente à profissionalidade, trouxemos autores como Maria do Céu Roldão, Sílvia de Paula Gorzoni, Claudia Davis, Neusa Banhara Ambrosetti, Patrícia Cristina Albieri de Almeida. Sobre os mestrados profissionais em educação e o desenvolvimento da docência profissional - Tânia Maria Hetkowski e a legislação brasileira.
\end{abstract}

Palavras-chave: Profissionalidade docente; Sociologia do Trabalho; Mestrados profissionais; Trabalho; Identidade.

\section{ABSTRACT}

The article focuses on highlighting the importance of recognizing professional teaching as an activity specifically assigned to teachers, given that they develop it during their lives in the exercise of their function. It aims to bring visibility to the teaching profession in order to make society value the work of Brazilian teachers, reflecting on the importance of a profession that is the basis for all others, as it is through the work of these agents of education that all professions develop. For this, we also seek to conceptualize the term "work", bringing contributions from the Sociology of Work and authors such as Ricardo Antunes, Ricardo Ramalho, Jacob Carlos Lima and Jacques Le Goff. With regard to professionalism, we brought authors such as Maria do Céu Roldão, Sílvia de Paula Gorzoni, Claudia Davis, Neusa Banhara Ambrosetti, and Patrícia Cristina

\footnotetext{
${ }^{1}$ SEDUC-MA (Secretaria de Estado da Educação do Maranhão)

*E-mail: walter.marques@prof.edu.ma.gov.br

${ }^{2}$ IFMA (Instituto Federal de Educação, Ciência e Tecnologia do Maranhão).

${ }^{3}$ SEMED (Prefeitura Municipal de Matões do Norte, Maranhão)

${ }^{4}$ UEMA (Universidade Estadual do Maranhão)

${ }^{5}$ UFMA (Universidade Federal do Maranhão)
} 
Albieri de Almeida. On professional master's degrees in education and the development of professional teaching - Tânia Maria Hetkowski and Brazilian legislation.

Keywords: Teaching professionality; Sociology of Work; Professional Masters; Work; Identity.

\section{INTRODUÇÃO}

O trabalho nem sempre foi visto com bons olhos. O trabalho está implicado como algo que é primordial à vida, uma vez que é por meio do trabalho que a produção e reprodução material e imaterial (cultura) se dá. O trabalho cria material e imaterialmente os meios com que a sociedade vive. Contudo, é contraditório em sua acepção, pois remete também à subordinação e alienação. Marx destaca que o trabalho foi crucial para a humanidade, contudo, o capitalismo o fetichizou, alienando-o e com isso alienando o trabalhador. Weber, na ética protestante dignifica o trabalho como bênção, símbolo de salvação (ANTUNES, 2011).

De acordo com Gorz (2003), o trabalho como o conhecemos e atribuímos como sustentáculo de nossa existência, individual ou em sociedade, é uma invenção do industrialismo. O trabalho enquanto promoção de coesão social e cidadania, antropologicamente, não pode ser considerado fator de integração social. O trabalho, para Platão, pertence ao campo da necessidade, portanto, fora da liberdade, pois todo aquele

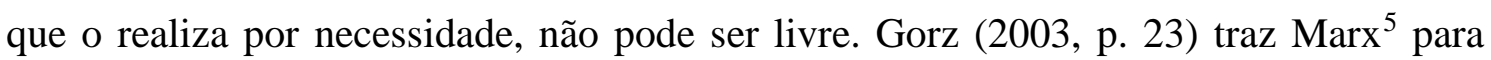
fundamentar que o reino da liberdade só pode ser alcançado quando o trabalho é realizado “[...] além da esfera da produção material”, ou seja, "[...] o trabalho que consiste em produzir e reproduzir as bases materiais necessárias à existência não pertence ao reino da liberdade". É o capitalismo manufatureiro do século XVIII que dá a acepção do trabalho como algo digno de ser realizado. E Marx o caracteriza como "trabalho abstrato", ou seja, o trabalho passa a ser descolado do trabalhador como algo externo a ele, “[...] Deixava de fazer parte da vida para tornar-se o meio de "ganhar a vida". (GORZ, 2003, p. 30). A racionalização econômica do trabalho revolucionou, ou seja, subverteu a vida, os valores, as relações sociais e com a natureza, de modo nunca visto. Foi uma invenção.

\footnotetext{
${ }^{5}$ Livro III d'O capital.
} 
Segundo Le Goff (2017), o termo trabalho como se conhece na atualidade, não existia até o século XV e a concepção atual do termo só surgiu no século XIX. Nesse primeiro momento, estabelece-se o vínculo da noção de trabalho com a de assalariado que, no final do século XV transforma a realidade econômica e social e, o vínculo entre trabalho e industrialização como advento do século XIX. A Idade Média traz, no plano do vocabulário, o termo trabalho oscilando entre duas acepções: a "do seu aspecto penoso, [...], não nobre, [...]," e o do "honroso porque criador" (LE GOFF, 2017, p. 624). Já no campo semântico, três termos e três noções, em latim:

Figura 1 - significado de trabalho

Em latim, na Idade Média, seu campo semântico desdobra-se em torno de três termos e três noções: labor, que significa inicialmente "pena", de onde laborare ("penar") e laborator ("aquele que pena"); ars, quer dizer, "arte", e daí artifex ("artesão"); enfim, opus ("obra"), da qual derivam operari ("criar uma obra") e operarius ("aquele que cria", mas que, por uma dessas inversões cujo segredo é mantido pela semântica histórica e revelado pela história global, acabará por designar em francês o trabalhador por excelência. o da indústria. o "operário").

Fonte - LE GOFF (2017)

$\mathrm{O}$ autor destaca que o mais interessante é que a palavra que vai ganhar notabilidade nos séculos XVI e XVII é travail [trabalho] derivando do baixo latim tripallium (instrumento de tortura). É na Idade Média que o trabalho, nos aspectos modernos, tomou forma na realidade material e social - associação do homem à ferramenta e da máquina - e, como consciência tanto de intelectuais e trabalhadores.

Le Goff destaca o trabalho em três aspectos e/ou pontos de vista: técnico, social e ideológico. Os aspectos técnicos se voltam para a vida cotidiana das cidades e da agricultura. Desenvolvem-se ferramentas para aperfeiçoar a lida com a terra e ferramentas para suavizar práticas citadinas que modificam a cidade inserindo tecnologias e modificando os aspectos visuais da cidade e a forma de lidar com tais inovações.

Os aspectos sociais do trabalho são, nos séculos XI, XII e XIII, causa e efeito da expansão do Ocidente. Tais aspectos modificam profundamente o campo e a cidade, transforma as relações, monetizando as trocas, assalariando o trabalho e contribuindo para o aumento vertiginoso da urbanização das cidades. A divisão do trabalho exige uma especialização no processo de produção. 
Já os aspectos ideológicos e mentais se encontram na Bíblia por meio do mosteiro como seu primeiro e principal lugar de aplicação. A sociedade cristã medieval herdou duas tradições opostas em relação ao valor do trabalho, uma que o valoriza, outra que o deprecia. O trabalho de Adão, antes da Queda, era viver no Paraíso. Por ter cometido o pecado, passou a viver do suor de seu rosto e Eva a sofrer no trabalho de parto. Um momento em que o trabalho é exaltado é quando o apóstolo Paulo profere que quem não trabalha não merece comer.

A valorização do trabalho no período carolíngio é incontestável. Busca melhorar o cultivo por meio do trabalho. "Por outro lado, a legislação carolíngia dos capitulares, retomando os textos dos códigos de Teodósio e Justiniano, instaura a caça aos vagabundos que não trabalham" (LE GOFF, 2017, p.634). "É entre os séculos XI e XIII que se afirma uma maior e mais profunda valorização do trabalho e dos trabalhadores". (LE GOFF, 2017, p. 634). Imagens metafóricas bíblicas como de Marta e Maria, respectivamente, exemplificadas por Jesus entre aquela que trabalha e aquela que não trabalha, são revisadas de forma a valorizar as duas personagens - ideologia. Outro exemplo destacado pelo autor é a profissão de São José que era ferreiro na tradição antiga e se torna carpinteiro na tradição bíblica.

O que se pode depreender da discussão levantada pelos autores supracitados é que o trabalho foi, é e sempre será necessário. Seja o trabalho, digno ou indigno, sem ele, a sociedade não existiria, pelo menos na forma como a conhecemos. Na lógica do trabalho como uma atividade destinada apenas aos indignos realizarem, uma vez que não pertencem à polis (símbolo de liberdade), mas à esfera do privado, estes o realizam por necessidade (quem tem necessidade, não é livre), seja por salário, seja para preservar a própria vida. Aos dignos, só lhes cabe usufruir dos frutos do trabalho.

A perspectiva acima retrata um ponto de partida das relações da sociedade com o trabalho, onde os "homens livres", pertencentes à polis (esfera pública) se colocaram como dignos e não poderiam, portanto, trabalhar, pois não necessitavam e, por outro lado, instituíram a esfera privada. Esta elegia o homem da polis, seu senhor, que detinha todo o poder sobre seus pertences (os escravos, as mulheres e crianças).

Outrossim, ainda que a manufatura outrora, pertencera ao campo da esfera privada, é justamente a manufatura que se industrializa e altera os sentidos do trabalho. É, por meio do industrialismo que o trabalho passa a ter conotações honoríficas. O trabalhador passa de mero destinado ao sofrimento e a viver do suor de seu rosto, tal como 
Adão, a exercer uma atividade que o dignifica e glorifica o próprio Deus ${ }^{6}$ (Weber, na Ética protestante e o espírito do capitalismo).

O trabalho na sociedade moderna ou industrial torna-se tão importante que necessitará de um campo de estudo que se dedique às suas implicações na sociedade. Embora os antigos tenham dissertado sobre o trabalho, como Platão, o fizeram apenas nos campos relacionados às esferas públicas e privadas, nas relações de suserania e vassalagem, pois ainda que houvesse um salário, era algo que em nada se compara à complexidade do salário nas atuais sociedades capitalistas. Portanto, a Sociologia é o campo teórico e epistemológico criado para lidar com a sociedade que se complexifica com o advento da industrialização.

E o subcampo Sociologia do Trabalho, é forjado com a complexidade que a sociedade industrial capitalista cria. Veja-se que a sociedade se expande com o surgimento da cidade que se complexifica em diversidade e quantidade de serviços e especializações. Isso faz com que a Sociologia eleja um subcampo específico para lidar, exclusivamente, com as questões relacionadas a ele - a Sociologia do Trabalho.

O objeto da Sociologia do Trabalho é o estudo da relação entre o trabalhador e o empregador. Tal relação implica nas condições de trabalho onde o empregador (dono dos meios de produção) e o empregado (dono da força de trabalho) duelam em condições desiguais e desfavoráveis de força e poder. Ramalho (2013) alerta que a Sociologia do Trabalho se desenvolveu teoricamente apenas considerando a díade - quem detém os meios de produção e quem detém a força de trabalho - relacionada ao trabalho regulado, assalariado, ou seja, o trabalho clássico.

Leite (2000) aponta a interdisciplinaridade para a formação do campo conceitual da Sociologia do Trabalho, uma vez que trata das implicações do trabalho em variados aspectos, sejam psicológicos, sociológicos, econômicos, com recortes de gênero, raça, entre outros. Segundo a autora, a constituição do campo de estudo da Sociologia do Trabalho se enriquece conceitualmente ao se utilizar dos pressupostos teóricometodológicos de outros campos de conhecimento, ou seja, agindo interdisciplinarmente. Contudo, destaca que é importante ancorar-se em outra disciplina, mas não extrapolar o conceito a ponto de tornar-se a outra. É preciso manter uma identidade disciplinar.

\footnotetext{
${ }^{6}$ Aquele que condenou Adão a viver de seu suor.
} 
Jacob Carlos Lima apresenta os fundamentos para a criação do subcampo da Sociologia - a Sociologia do Trabalho - destacando Marx, Weber e Durkheim e a Sociologia francesa e americana como base para tal criação. A partir dos modelos industriais de Taylor, que considerava que o trabalhador deveria ser "bovino" (se não pensa é mais produtivo) e, Ford, que racionaliza o trabalho, voltando-se para as condições sociais e psicológicas do trabalhador, como moradia perto da fábrica, salário para suprir necessidades básicas, faz com que as ciências humanas e sociais adentrem o espaço da fábrica. Segundo Jacob Lima, a racionalização do trabalho no modelo Toyotista insere o trabalhador como sinônimo de cidadão, enfatiza o trabalho como símbolo de posição social. Destaca a carteira de trabalho como justificativa social de que a pessoa é trabalhadora, portanto, possui o status de cidadão.

Os três autores que embasam essa discussão da criação e fundamentação do subcampo da Sociologia - a Sociologia do Trabalho - destacam a flexibilização do trabalho como precarização do trabalho, perda de direitos.

Ramalho (2013) reflete sobre as pesquisas feitas no campo da Sociologia do Trabalho e destaca que são todas, basicamente, voltadas para as relações do trabalho clássico, ou seja, do trabalho assalariado. O autor alerta que há um outro campo quase inexplorado de pesquisas no tocante à Sociologia do Trabalho, que é a extensão da dimensão do trabalho que não se relaciona com o trabalho assalariado, as práticas informais, flexíveis, atípicos, não estruturados, - "trabalho não clássico". Ramalho (2013, p. 96 apud De La GARZA, 2011) reflete sobre a não consideração de questões que se relacionam com a dimensão do trabalho fora do trabalho clássico, onde os trabalhadores não são '[...] capazes de constituir identidades coletivas, projetos ou sujeitos coletivos', vislumbrando um futuro de fragmentação e redução ao individual". Os autores destacam a necessidade de discutir uma ampliação do conceito de trabalho. Eis que nessa lógica cabe discutir os meandros da flexibilização do trabalho, onde o trabalhador informal precisa buscar um eixo que o encaixa como uma coletividade, ainda que seja um trabalhador individual ou empresário de si - uberização ou precarização do trabalho(?).

Jacob Carlos Lima, José Ricardo Ramalho e Márcia de Paula Leite estão discutindo as questões que se relacionam com o trabalho da supermodernidade, da flexibilização das condições de trabalho, consequentemente, de perdas de direitos sociais e humanos. José Ricardo Ramalho destaca que esse campo de pesquisa carece de mais atenção, que a Sociologia do Trabalho deve buscar nas entrelinhas dessas novas formas 
de trabalho, das relações em que o panorama atual coloca o indivíduo. e o mesmo pode ser percebido nas discussões de Márcia de Paula Leite. E, vale destacar que, as reflexões de Ramalho remetem a um retorno a Taylor. Jacob Carlos Lima destaca, principalmente, no tocante às dificuldades de pesquisa, a entrada do pesquisador na fábrica.

Situada a discussão sobre a origem e as formas como foram concebidas o trabalho nas sociedades antigas e modernas assim como as concepções e conotações que esse tomou na sociedade industrial, cabe situar o professor e a professora como atores dessa cena em que nem sempre atuam como protagonista, mas exatamente o oposto disso, sendo, muitas vezes, pintados como os vilões.

Os profissionais da educação estão situados na sociedade capitalista neoliberal, industrial e pós-industrial, moderna ou pós-moderna (termos ainda em discussão, pois autores como Hannah Arendt ${ }^{7}$, Jean-François Lyotard ${ }^{8}$, David Harvey ${ }^{9}$, Bruno Latour ${ }^{10}$, Anthony Giddens ${ }^{11}$ etc. são alguns dos muitos que questionam essas classificações e medições do tempo assim como o próprio desenvolvimento da humanidade que é posto em xeque). Uma vez que fazem parte desse misto econômico-social, é preciso estar situados contextualmente com as relações de trabalho, os conceitos de classe, o enquadramento em nichos específicos a cada atividade laboral exercida etc. É preciso, pois que o professor e a professora sejam vistos como pertencentes a uma classe de trabalhadores, uma vez que já estão inseridos no mercado de trabalho e nem sempre são reconhecidos como trabalhadores. Portanto, há a necessidade de conceituar a prática dos professores, de profissionalizar seus fazeres conceitualmente, pois na prática já está a muito tempo. Portanto, o termo profissionalidade docente, derivado de profissão e apropriado pelo campo da educação, começa a surgir em pesquisas sobre professores a partir dos anos de 1990. Antes disso, as pesquisas buscavam compreender a atividade docente. $\mathrm{O}$ conceito de profissionalidade surge para ampliar essa compreensão assim como articular profissionalidade a profissionalização (AMBROSETTI; ALMEIDA, 2009; GORZONI; DAVIS, 2017). Embora a busca do reconhecimento se dê por vias

\footnotetext{
${ }^{7}$ ARENDT, Hannah. A condição humana. Trad. Roberto Raposo; posfácio Celso Lafer. - 10. ed. - Rio de Janeiro: Forense Universitária, 2007.

${ }^{8}$ LYOTARD, Jean-François. A condição pós-moderna. Trad. Ricardo Corrêa Barbosa; posfácio: Silviano Santiago - 12. ed.- Rio de Janeiro: José Olympio, 2009.

${ }^{9}$ HARVEY, David. Condição pós-moderna. 17. ed. [2008]. - São Paulo: Edições Loyola, 1992. 349 p.

${ }^{10}$ LATOUR, Bruno. Jamais fomos modernos: ensaio de antropologia simétrica. Trad. Carlos Irineu da Costa. - Rio de Janeiro: Editora 34, 1994.

${ }^{11}$ GIDDENS, Anthony As conseqüências da modernidade. Trad. Raul Fiker. - São Paulo: Editora UNESP, 1991. - (Biblioteca básica).
} 
neoliberais, pois as reformas empreendidas nos anos de 1990 tenham esse cunho (SHIROMA; EVANGELISTA, 2003), ainda assim é válida, pois buscar situar o trabalho dos profissionais da educação em categorias trabalhistas, o que fortalece a luta por direitos sociais, econômicos e profissionais.

Segundo Gorzoni e Davis (2017), Contreras (2012) relaciona autonomia e profissionalidade, afirmando que autonomia no ensino é uma necessidade educativa e direito trabalhista e ressalta que outros autores utilizam o termo profissionalidade objetivando recuperar as qualidades do profissional em seus fazeres específicos. Para Contreras, a profissão docente está imbricada em condições sociopolíticas e pode ser definida em três dimensões, a saber: "obrigação moral, compromisso com a comunidade e competência profissional". (GORZONI; DAVIS, 2017, p. 1400).

A primeira “[...] está associada ao compromisso com a ética da profissão, ao compromisso com o desenvolvimento e ao reconhecimento do valor do aluno". A segunda dimensão “[...] está relacionado à possibilidade de equacionar as expectativas sociais ao currículo, mediar conflitos e lidar com questões sociopolíticas que interferem no ofício de ensinar”. Já em relação à terceira, “[...] refere-se aos recursos intelectuais empregados na construção do repertório de conhecimentos profissionais, habilidades e técnicas para desenvolver a ação didática, [...]”. (GORZONI; DAVIS, 2017, p. 1400).

Apesar do professor representar uma figura central nos processos educacionais, “A elaboração prévia dos currículos feita por especialistas, a dependência das coordenadas político-administrativas e as influências do setor econômico e da sociedade colaboram para que a profissão docente seja considerada semiprofissão". (SACRISTÁN, 1995 apud GORZONI; DAVIS, 2017, p. 1401). Segundo Sacristán (1995), o professor não deve ser visto como improvisador, técnico, mas um profissional que utiliza conhecimento/experiências no campo em que atua. "A prática educativa oferece indícios sobre o processo de ensino-aprendizagem, a ação didática e a prática pedagógica visível e não visível, ou seja, valores, atitudes, crenças, competências, etc.” (GORZONI; DAVIS, 2017, p. 1401).

Roldão (2008), recomenda que se diga desenvolvimento profissional - que seria a profissionalidade - em vez de profissionalização, uma vez que este movimento está circunscrito à formação inicial terminando com a certificação de competência reconhecida para exercer a profissão docente [graduação]. Roldão entende que a profissionalidade é um processo que acompanhará o docente em toda a sua trajetória 
enquanto professor (GORZONI; DAVIS, 2017). Segundo Roldão (2008) existem quatro descritores de profissionalidade, todos em permanente reconstrução, a saber: a especificidade da função [natureza específica, utilidade e reconhecimento social], o saber específico [saber próprio e profissional], o poder de decisão [controle e autonomia quanto à atividade e consequente responsabilidade social e pública] e o pertencimento a um corpo coletivo [reconhecimento dos pares que defendem status, credibilidade, exclusividade de saber próprio e definição de quem pode ou não exercer tal atividade]. (2007 apud GORZONI; DAVIS, 2017, p. 1402, grifo nosso).

Roldão (2021, p. 82) destaca que em 2007 a Comissão Europeia apresentou ao Conselho e ao Parlamento Europeus, documento intitulado: "Para o Desenvolvimento da Qualidade da Formação de Professores", enunciando "[...] quatro princípios para o desenvolvimento da competência e qualidade da formação de professores [...], destacando dois desses princípios, quais sejam: “[...] (1) à qualificação superior dos professores e correspondente expectativa de elevado nível do seu conhecimento, e (2) à sua condição de lifelong learners, vinculados pela natureza profissional do seu trabalho, ao imperativo da atualização e construção permanentes de conhecimento". Com isso, a autora elucida que o conhecimento profissional do professor diz do saber ensinar, ou seja, diz da competência profissional do professor, pois é preciso estabelecer certo rigor à função e ao saber para que se possa distinguir a atividade docente. Isso configura os seguintes questionamentos: “[... 1) O que faz um professor? O que define a sua ação profissional? 2) Que precisa ele de saber para desempenhar bem a função em causa?”. (ROLDÃO, 2021, p. 82)

Segundo André e Placco (2007 apud GORZONI; DAVIS, 2017) a profissionalidade docente consiste na busca de uma especificidade da profissão docente. Ou seja, “[...] diz respeito aos conhecimentos, comportamentos, habilidades, atitudes e valores que definem o educador, pressupondo a construção de uma identidade profissional que influencia e é influenciada nos contextos de trabalho" (GORZONI; DAVIS, 2017, p. 1404). Uma vez que a profissionalidade está diretamente relacionada com o conjunto de ações que formam a identidade profissional, tem-se uma profissionalização, pois esse arcabouço de conhecimentos definem os atributos e ferramentas de trabalho do professor. "Portanto, se a profissionalidade é desenvolvida, a profissionalização é conquistada" (GORZONI; DAVIS, 2017, p. 1404). Logo, a profissionalidade docente é o desenvolvimento da identidade do 
educador/professor/docente conquistado no campo de trabalho, sendo, pois, seu capital social, cultural e profissional. “[...], a profissionalidade docente e a identidade profissional do professor caracterizam-se como um conjunto de valores, conhecimentos, atitudes e habilidades necessários para conduzir o processo de ensino-aprendizagem nas escolas, orientando, assim, a especificidade do trabalho docente". (LIBÂNEO, 2015 apud GORZONI; DAVIS, 2017, p. 1405).

Ambrosetti e Almeida (2009) afirmam que a profissionalidade se inicia na escolarização básica, atravessa a formação profissional e atinge o professor em sua vida profissional presente, na organização escolar em que atua.

A ideia que subjaz às expressões profissionalidade e profissionalização é a da docência como um processo de constituição e identificação profissional, desenvolvido pelos professores ao longo de sua trajetória, nos diferentes espaços de socialização, desde a escolarização básica, passando pela formação profissional e, principalmente, na organização escolar, onde os professores exercem e aprendem a profissão. (AMBROSETTI; ALMEIDA, 2009, p. 595).

Portanto, Roldão (2008), Ambrosetti e Almeida (2009), Gorzoni e Davis (2017), partem do pressuposto de que a profissionalidade é um processo de construção do profissional docente. Essa construção não cessa para aqueles que estão em atividade, pois a atuação pressupõe uma constante atualização. O profissionalizar-se não considera uma atitude estanque, mas exatamente um acompanhamento da sociedade no espaço e no tempo de atuação, considerando políticas sociais e econômicas e, as epistemologias.

\title{
MESTRADOS PROFISSIONAIS
}

\begin{abstract}
A identidade profissional docente se constitui como uma interação entre a pessoa e suas experiências individuais e profissionais. A identidade se constrói e se transmite. E existem algumas características ou constantes da identidade profissional docente que se repetem e que são, geralmente, independentes do contexto social ou cultural. (MARCELO, 2009, p. 109).
\end{abstract}

A Pós-graduação stricto sensu no Brasil é regulamentada em 1965 e até 1995, a ênfase era somente em mestrados e doutorados acadêmicos. Essa modalidade não objetiva a intervenção, "os quais não têm na sua gênese o objetivo, prioritário, a ênfase da pesquisa de intervenção, estudos e avaliação, impactos e resolução de problemas, diretamente ou através de intensa imersão nas dinâmicas da rede da Educação Básica" (HETKOWSKI, 2016, p. 12). 
A Portaria $n^{\circ} 47$ de 17 de outubro de 1995 é endossada pelo Presidente da Fundação Coordenação de Aperfeiçoamento de Pessoal de Nível Superior (CAPES), objetivando legitimar Programas de Flexibilização do Modelo de Pós-graduação Senso Estrito em Nível de Mestrado, aprovado pelo Conselho Superior em sessão de 14/09/95 (BRASIL, 1995) $)^{12}$, os quais sinalizam a criação de outras modalidades de PPG, em especial a modalidade profissional. O Presidente da Capes resolve:

Determinar a implantação na Capes de procedimentos apropriados à recomendação, acompanhamento e avaliação de cursos de mestrado dirigidos à formação profissional, nos termos do referido documento, e do Parecer que o fundamentou, destacando-se que, para assegurar níveis de qualidade comparáveis aos vigentes no sistema de pós-graduação e consistentes com a especificidade dos cursos, ficam estabelecidos os requisitos e condicionantes seguintes:

1. A instituição proponente deve demonstrar possuir condições favoráveis ao desenvolvimento consistente e de longo alcance do ensino de pós-graduação, assegurando-lhe profundidade e perspectiva adequadas. 2. Os docentes e orientadores devem ser portadores do título de doutor ou de qualificação profissional inquestionável. Dos docentes doutores se exigirá que tenham produção intelectual de alto nível, divulgada de acordo com os padrões reconhecidos para sua área de conhecimento. Os docentes selecionados por qualificação profissional poderão atuar como co-orientadores. Eles deverão constituir uma parcela restrita do corpo docente, e sua escolha deve ser pertinente aos objetivos do curso, cuidadosamente justificada, documentada e controlada; as condições de trabalho e de carga horária, embora sem exigirem dedicação integral, devem ser compatíveis com as necessidades do curso. 3. O curso deverá articular as atividades de ensino com as aplicações de pesquisas, em termos coerentes com seu objetivo, de forma diferenciada e flexível. A existência de pesquisa de boa qualidade na instituição e de projetos em parceria com o setor produtivo, bem como a oferta de atividades de extensão, são requisitos essenciais ao credenciamento institucional para oferta deste tipo de curso. 4. A estrutura curricular deve ser clara e consistentemente vinculada à especificidade do curso e ser compatível com um tempo de titulação mínimo de um ano. 5. O estudante deve apresentar trabalho final que demonstre domínio do objeto de estudo e capacidade de expressar-se lucidamente sobre ele. De acordo com a natureza da área e com a proposta do curso, esse trabalho poderá tomar formas como, entre outras, dissertação, projeto, análise de casos, performance, produção artística, desenvolvimento de instrumentos, equipamentos e protótipos. (BRASIL, 1995).

Ampliando as regulamentações e legitimações dos MPs, a Portaria n ${ }^{\circ} 80$ de 16 de dezembro de 1998, publicada no Diário Oficial de 11/01/99, Seção I, pág. 14, dispõe

\footnotetext{
${ }^{12}$ Disponível em: https://abmes.org.br/arquivos/legislacoes/Portaria-Capes-47-1995-10-17.pdf.
} 
sobre o reconhecimento dos MP e, no item b, destaca "a relevância do caráter de terminalidade, assumido pela modalidade de Mestrado que enfatize o aprofundamento da formação científica ou profissional conquistada na graduação, aludido no Parecer ${ }^{\circ} 977$, de 03/12/65, do Conselho Federal de Educação”. (BRASIL, 1998) ${ }^{13}$.

Diante das possibilidades de inovar a PPG, a CAPES vem mostrar o crescimento dos MPs no Brasil, enfatizando a singularidade dessa trajetória: em 1999 havia apenas 04 cursos, impulsionando o crescimento para 62 em 2003, alcançando um quantitativo de $184 \mathrm{em}$ 2007, com um saldo de 338 em 2011 e, hoje, são reconhecidos e recomendados, aproximadamente, $600 \mathrm{MP}$, o que demonstra a ampliação, a importância e o reconhecimento como Programas de PósGraduação reconhecidos e inovadores. (HETKOWSKI, 2016, p. 13).

Com o crescimento dos MPs em diferentes instâncias de atuação, a Área de Educação inicia o processo de implantação nessa modalidade, sendo aprovado em 2009 o primeiro Mestrado Profissional em Educação (MPE) no Brasil, vinculado à Universidade Federal de Juiz de Fora (UFJF), com ênfase na Gestão e Avaliação da Educação Pública, homologado pelo Conselho Nacional de Educação (CNE) em 2010 e Portaria do Ministério de Educação e Cultura (MEC) $\mathrm{n}^{\circ} 1045$ de 18/08/2010, Diário Oficial 19/08/10; seguido pelo Programa de PósGraduação Gestão e Tecnologias Aplicadas à Educação da Universidade do Estado da Bahia (UNEB), recomendado pela CAPES através do Ofício ${ }^{\circ}$ 039-11/2010/CTC/CAAII/CGAA/DAV/CAPES. (HETKOWSKI, 2016, p. 14-15).

Tomamos como principal fonte norteadora para dissertar sobre Mestrados Profissionais, a pesquisa de Tânia Maria Hetkowski (2016). Contudo, outras pesquisas se juntam ao marco teórico para engrossar o caldo pedagógico sobre a política educacional brasileira, sobretudo, no que se refere aos Programas de Pós-Graduação Profissionais.

O interesse em estabelecer relações entre a Sociologia do Trabalho ao campo da Educação, especialmente, aliar os MPs (Mestrados Profissionais) à discussão da profissionalidade e profissionalização docente. Destaca-se que a proposta desses Programas, os quais têm por premissa, aplicar a pesquisa no local de estudo, tecendo o produto a partir dessa pesquisa empírica, busca conectar a teoria à empiria, construindo um profissional forjado na realidade. Embora munido de referenciais teóricos a priori, o tecido da pesquisa empírica traz em seu conjunto, as especificidades da docência apontados por Roldão (2008): a especificidade da função, o saber, o poder de decisão e o

\footnotetext{
${ }^{13}$ Disponível em: http://cad.capes.gov.br/ato-administrativo-detalhar?idAtoAdmElastic=858\#anchor.
} 
pertencimento a um corpo coletivo. O profissional desenvolve o senso de conhecimento a partir da experiência apontada por Dewey (2010).

Conforme Hetkowski (2016), havia um Mestrado Profissional em Educação do Maranhão em nível federal. A autora faz o seguinte destaque: "Hoje, 2016, temos aproximadamente 160 Programas de Pós-Graduação na Área da Educação, sendo que 38 são Mestrados Profissionais, os quais representam 19\% de todos os Programas da Área reconhecidos e recomendados pela CAPES em todo o Brasil (HETKOWSKI, 2016, p. 17). Destacamos a Portaria $n^{\circ}-919$, de 18 de agosto de 2016, que reconhece o MP Gestão de Ensino da Educação Básica, da Universidade Federal do Maranhão. (BRASIL, 2016). O Programa é conhecido pelo nome de PPGEEB/UFMA (Programa de Pós-Graduação em Gestão de Ensino da Educação Básica).

Os MPE devido sua identidade "ser" acadêmica e profissional da Área de Educação, contêm uma relação intrínseca com as redes de ensino, pois adentram nos problemas que desafiam os profissionais que atuam nos processos educacionais, uma vez que a "educação compreende o ensino, mas transcende como projeto de formação e, neste sentido, os conteúdos ensinados/apreendidos ganham sentido na interação com as experiências vividas na escola e fora dela." (CAPES, 2013, p. 06). (HETKOWSKI, 2016, p. 18-19).

Pode-se inferir que os MPE (Mestrado Profissional em Educação) criam capital educacional, mas também, social, cultural e econômico? Partindo do pressuposto de que a vivência da pesquisa dos MPE cria e recria laços afetivo-sociais entre a escola e o pesquisador e, que juntos, elaboram uma pesquisa perspectivada no sentido em que foi forjada na realidade empírica para ser experimentada, enquanto fruto de reflexões, no mundo externo.

Assim, os MPE investem e mobilizam pressupostos teóricometodológicos às pesquisas de intervenção a resolução de problemáticas específicas do contexto da educação, bem como têm como compromisso atuar na formação dos profissionais ao aprimoramento de práticas pedagógicas, estratégias e técnicas de ensino, redimensionar um "saber-fazer crítico-reflexivo, científico" e não repetitivo-tecnicista, concebendo condições aos profissionais dessa área e, possibilidades de ampliação nos modos de fazer, já existentes, ou criando novas formas, estratégias e inovações na rede básica de ensino. (HETKOWSKI, 2016, p. 19).

Os MPE têm como campo de trabalho, essencialmente e especialmente, a Educação Básica de Ensino e as esferas de atuação, visando atender às demandas das comunidades e seu entorno, efetivar parcerias entre as instituições de ensino e, suscitar ações que mobilizem pesquisadores, 
alunos e profissionais do campo da Educação em parceria com outros profissionais que atuam, direta ou indiretamente nesta área, mas que coadunam suas teorias e práticas às demandas educacionais. Nesse ínterim, compreendemos que os processos formativos que envolvem as universidades e outros níveis de ensino incidem, diretamente, nos meandros da Educação Básica. Educação Básica entendida como sustentação de outros níveis de ensino e, nisso concerne à preocupação e o compromisso dos MPE com a Educação Infantil, Ensino Fundamental, Ensino Médio e com os profissionais que atuam neste cenário. As pesquisas aplicadas têm como escopo a delimitação e a relevância de situações específicas e potenciais de aplicabilidade, ou seja, quando mais definido o objeto de pesquisa, o lócus, os sujeitos e a metodologia de intervenção, melhor a qualificação do trabalho e das possibilidades de utilização dos conhecimentos em ações e, consequentemente, os resultados. (HETKOWSKI, 2016, p. 19).

Fernandes e Nunes (2016) vêm destacar o papel dos mestrados profissionais em educação em resposta ao questionário de avaliação de desempenho dos Programas de Pós-Graduação Stricto Sensu no Brasil a partir do quesito Inserção Social da Coordenação para Aperfeiçoamento de Pessoal de Educação Superior (CAPES). Segundo Marques et al. (2020, p. 97694) “Os autores elucidam que o ganho desse questionário para a educação seria o grande impacto da transformação social, uma vez que os programas Stricto Sensu teriam, no tocante à responsabilidade social, que oferecer uma devolutiva em forma de pesquisas".

As pesquisas de intervenção, segundo a Portaria Normativa $n^{\circ}$ 07/09, pressupõem a utilização aplicada dos conhecimentos teórico-práticos educacionais e o exercício da inovação de práticas e de processos na área de educação, visando à valorização da experiência dos profissionais que atuam nestes espaços. Assim, as metas de investigação, no que concerne aos princípios dos MPE, parte da relação empírico-prática, ou seja, a realidade empírica é um elemento essencial para que o pesquisador, profissional da educação, análise, compreenda, proponha e intervenha. Assim, a realidade educacional é o ponto de partida e de chegada, [...], (HETKOWSKI, 2016, p. 20).

Hetkowski (2016) traz Gatti (1999) para corroborar com a essência dos MPE (Mestrado Profissional em Educação).

A compreensão deste agir intencional, destas formas de intervenção no real que é de caráter profissional, requer um outro tipo de conhecimento, aquele conhecimento que diz respeito à relação/incorporação de teorias com/em práticas intencionais, com finalidades socialmente definidas. A reflexão, o estudo, a investigação sobre seus modos de intervir é que constitui sua área privilegiada de construção de conhecimento. Aí encontramos suas especificidades. Nem por isso seus estudos perdem o caráter científico, ao contrário, é 
neste recorte que sua contribuição é insubstituível. (GATTI, 1999 apud HETKOWSKI, 2016, p. 21).

Tendo sido revogadas todas as portarias anteriores, quais sejam: Portaria n. 47/95; Portaria n. 80/98; Portaria n. 131/17, está em vigor a Portaria n. 60/2019 (atualizada em 02 de abril de 2021). No entanto, sobre o reconhecimento de doutorado em nível profissional, é a Portaria 131/2017, a que traz essa regulamentação:

Art. $1^{\circ}$ A Coordenação de Aperfeiçoamento de Pessoal de Nível Superior, CAPES, regulamentará a submissão de propostas de cursos novos de pós-graduação stricto sensu na modalidade profissional, em nível de mestrado e de doutorado, por meio de portarias e regulamentos próprios. (BRASIL, 2017).

Quanto à Portaria atual (60/2019), alterou-se algumas palavras, mas a essência do texto permaneceu, posto que buscava dispor sobre a regulamentação para proposta em nível de doutorado.

Art. $1^{\circ}$ A Coordenação de Aperfeiçoamento de Pessoal de Nível Superior - CAPES regulará a submissão de propostas de cursos novos de pós-graduação stricto sensu na modalidade profissional, em nível de mestrado e de doutorado, e avaliará os cursos oferecidos, na forma desta Portaria e de sua regulamentação própria. (BRASIL, 2019).

Faz-se um destaque quanto aos produtos das pesquisas realizadas no âmbito dos Programas Profissionais (Mestrado e Doutorado) que pautados na premissa da inovação, a Portaria abre a possibilidade de realizar-se a pesquisa empírica e dos formatos de realização dos trabalhos de conclusão do curso.

\section{CAPÍTULO IV}

\section{DOS TRABALHOS DE CONCLUSÃO DE CURSO}

Art. 11 Os trabalhos de conclusão dos cursos profissionais deverão atender às demandas da sociedade, alinhadas com o objetivo do programa, utilizando-se o método científico e o estado da arte do conhecimento, seguindo-se os princípios da ética.

Parágrafo único. O regulamento do programa Profissional deverá indicar os formatos dos trabalhos de conclusão, assim como os mecanismos de registro documentado sobre o conhecimento gerado pela pesquisa, para fins de verificação e avaliação.

Art. 12. As orientações específicas para os formatos dos trabalhos de conclusão serão explicitadas nos documentos orientadores de cada área de avaliação, permitindo formatos inovadores, com destaque para a relevância, inovação e aplicabilidade desses trabalhos para o segmento da sociedade na qual o egresso poderá atuar. (BRASIL, 2019). 
Inferindo sobre o que dispõe a Portaria n. 60/19, destaca-se algumas produções de trabalhos empíricos e da consequente dissertação realizadas no âmbito do PPGEEB/UFMA (Programa de Pós-Graduação em Gestão de Ensino da Educação Básica) da Universidade Federal do Maranhão. As pesquisas são todas realizadas de forma empírica com aplicação no local objeto do estudo (como rege a norma) e os formatos de apresentação do produto variam, podendo ser manuais, cartilhas, Apps (Aplicativos online), sites etc. e finalizam com a escrita de uma dissertação que deve ser apresentada/defendida para que o/a discente receba o título de Mestre/Mestra.

Pensando na inovação, quais outros formatos seriam possíveis para serem desenvolvidos no âmbito dos Programas Profissionais?

\section{CONSIDERAÇÕES FINAIS}

Consideramos que para se buscar a identidade profissional docente, é preciso situar os professores e professoras em seu campo de trabalho. É preciso identificar e explicitar o que é que esses profissionais fazem e que é diferente de outros fazeres (ROLDÃO, 2007; 2021). Logo, é preciso dizer quais são as ferramentas de trabalho dos professores e professoras.

Cada professor e professora têm, obviamente, suas subjetividades, modos de ensinar próprios, mas todos devem ter tido contato com a cultural geral antes de ir à sala de aula. A profissionalidade perpassa pela posse de alguns atributos específicos da docência e, conforme explicitado acima, pelos autores e autoras, a constante atualização desses atributos constitui a profissionalidade, pois a profissão é conquistada quando essa condição de conhecimentos e desenvolvimento acontece.

No intuito de embasar a discussão sobre como professores e professoras adquirem o estatuto de profissionais e consequentemente sua profissionalidade, trouxemos para dialogar: teóricos da Sociologia do Trabalho para elucidar os conceitos de trabalho assim como discorrer sobre o trabalho no tempo e no espaço e, teóricos da Educação no que se refere à profissionalização desses atores da sala de aula, especialmente, os da educação básica. Dialogamos também com a legislação oficial que reconheceu e recomendou os Programas Profissionais como meios para a busca da profissionalização docente. 
Esperamos que este artigo se junte aos outros que já discutem a escola como um caminho possível para o desenvolvimento de subjetividades e coletividades, de pessoas, do mundo, de consciências, de alteridades, de empatias, - inclusão.

\section{REFERÊNCIAS}

ABMES (Associação Brasileira de Mantenedoras de Ensino Superior). https://abmes.org.br/legislacoes/detalhe/2184/portaria-capes-n-47. Acesso em: 20 nov. 2021.

AMBROSETTI, Neusa Banhara; ALMEIDA, Patrícia Cristina Albieri de. Profissionalidade docente: uma análise a partir das relações constituintes entre os professores e a escola. Revista Brasileira de Estudos Pedagógicos, Brasília, v. 90, n. 226, p. 592-608, set./dez. 2009. Disponível em:

http://rbep.inep.gov.br/ojs3/index.php/rbep/article/view/976. Acesso em: 10 dez. 2021.

ANDRÉ, Marli Eliza Dalmazo Afonso de; PLACCO, Vera Nigro de Souza. Processos psicossociais na formação de professores: um campo de pesquisas em Psicologia da Educação. Contrapontos, Itajaí, v. 7, n. 2, p. 339-346, maio/ago. 2007. Disponível em: http://educa.fcc.org.br/scielo.php?script=sci_arttext\&pid=S1984-

71142007000200009\&lng=en\&nrm=iso\&tlng=pt. Acesso em: 10 dez. 2021.

ANTUNES, Ricardo. Trabalho. In: CATTANI, David; HOLZMANN, Lorena (Org.). Dicionário de Trabalho e Tecnologia. 2. ed. Porto Alegre, RS: Zouk, 2011, p. 433437.

BRASIL. Portaria no 47, de 17 de outubro de 1995. CAPES/MEC (Coordenação de Aperfeiçoamento de Pessoal de Nível Superior - CAPES/Ministério da Educação).

Disponível em: http://cad.capes.gov.br/ato-administrativodetalhar?idAtoAdmElastic=1054\#anchor. Acesso em: 20 nov. 2021.

BRASIL. Portaria n⿳ 80, de 16 de dezembro de 1998. CAPES/MEC (Coordenação de Aperfeiçoamento de Pessoal de Nível Superior - CAPES/Ministério da Educação). Disponível em: http://cad.capes.gov.br/ato-administrativodetalhar?idAtoAdmElastic=858\#anchor. Acesso em: 20 nov. 2021.

BRASIL. Portaria no 919, de 18 de agosto de 2016. MEC (Ministério da Educação). Publicado no Diário Oficial da União - Seção 1, p. 13, n 160, sexta-feira, 19 de agosto de 2016. Disponível em:

https://sigaa.ufma.br/sigaa/public/programa/documentos_stricto.jsf?lc=pt_BR\&idProgra

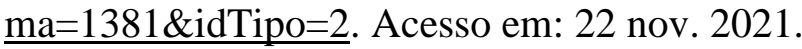

BRASIL. Portaria no 131, de 28 de junho de 2017. CAPES/MEC (Coordenação de Aperfeiçoamento de Pessoal de Nível Superior - CAPES/Ministério da Educação). Disponível em: http://cad.capes.gov.br/ato-administrativodetalhar?idAtoAdmElastic=1051\#anchor. Acesso em: 20 nov. 2021. 
BRASIL. Portaria n⿳0 60, de 20 de março de 2019. CAPES/MEC (Coordenação de Aperfeiçoamento de Pessoal de Nível Superior - CAPES/Ministério da Educação). Disponível em: http://cad.capes.gov.br/ato-administrativodetalhar?idAtoAdmElastic=884\#anchor. Acesso em: 20 nov. 2021.

CONTRERAS, José. A autonomia de professores. Tradução de Sandra Trabucco Venezuela. 2. ed. São Paulo: Cortez, 2012.

DEWEY, John. Arte como experiência. Trad. Vera Ribeiro. - São Paulo: Martins Fontes, 2010. - (Coleção Todas as Artes).

FERNANDES, Vanja Maria Dominices Coutinho; NUNES, Antonio de Assis Cruz. A inserção social no contexto dos mestrados profissionais: um olhar retrospectivo e prospectivo. Plurais - Revista Multidisciplinar, Salvador, v. 1, n. 3, p. 29-45, ago./dez. 2016. Disponpivel em:

https://revistas.uneb.br/index.php/plurais/article/view/3056. Acesso em: 10 dez. 2021.

GORZ, André. A invenção do trabalho. In: Metamorfoses do trabalho: crítica da razão econômica. São Paulo: Annablume, 2003, p. 21-31.

GORZONI, Sílvia de Paula; DAVIS, Claudia. O conceito de profissionalidade docente nos estudos mais recentes. Cadernos de Pesquisa, v. 47 n. 166, p. 1396-1413, out./dez. 2017. Disponível em:

https://www.scielo.br/j/cp/a/wQ9fQZq8sDY9cnSng5fxVFd/abstract/?lang=pt. Acesso em: 10 dez. 2021.

HETKOWSKI, Tânia Maria. MESTRADOS PROFISSIONAIS EDUCAÇÃO: Políticas de implantação e desafios às perspectivas metodológicas. Plurais - Revista interdisciplinar - Salvador, v. 1, n. 1, p. 10-29, jan./abr. 2016. Disponível em: https://revistas.uneb.br/index.php/plurais/article/view/2299. Acesso em: 10 dez. 2021.

LE GOFF, Jacques. Trabalho. In: LE GOFF, Jacques; SCHMITT, Jean-Claude (Org.). Dicionário analítico do Ocidente medieval: v. 2. São Paulo: Editora UNESP, 2017, p. 624-638.

LEITE, Marcia de Paula. Trabalho e sociedade em transformação. Sociologias, Porto Alegre, ano 2, n. 4, jul./dez 2000, p. 66-87. Disponível em:

https://www.scielo.br/j/soc/a/nvYc8SmJbs6JsrbgpKxmCjr/?lang=pt. Acesso em: 10 dez. 2021.

LIBÂNEO, José Carlos. Organização e gestão da escola: teoria e prática. 6. ed. rev. e aum. São Paulo: Heccus, 2015.

LIMA, Jacob Carlos. Conversas Metodológicas - Sociologia do Trabalho: Constituição do Campo (ClickCiência UFSCar) Videoconferência do Prof. Dr. Jacob Carlos Lima da UFSCAR (Youtube). Disponível em: https://www.ds.ufscar.br/esta-noar-a-segunda-edicao-da-serie-conversas-metodologicas/. Acesso em: 20 nov. 2021.

MARCELO, C. A identidade docente: constantes e desafios. . Formação Docente Revista Brasileira de Pesquisa sobre Formação de Professores, [Internet]. $9^{\circ} \mathrm{de}$ 
maio de 2009 [citado $10^{\circ}$ de dezembro de 2021]; v. 1, n. 1, p. 109-131. Disponível em: https://revformacaodocente.com.br/index.php/rbpfp/article/view/8.

MARQUES, Walter Rodrigues; FERREIRA, Diego Jorge Lobato; CUTRIM, Dayana Sthéfane Pereira; VIANA, Maria Neuraildes Gomes; FREITAS, Marizelia Dielle de; COSTA, Rosangela Coêlho; ROCHA, Luís Félix de Barros Vieira; SOARES, Hérbia Araújo. Profissionalidade docente: Saber e busca de reconhecimento. Braz. J. of Develop., Curitiba, v. 6, n.12, p.97692-97711 dec. 2020. Disponível em: https://www.brazilianjournals.com/index.php/BRJD/article/view/21544/17184. Acesso em: 10 dez. 2021.

RAMALHO, José Ricardo. Trabalho e desafios da pesquisa sociológica. Revista Brasileira de Sociologia. v.1, n.1 - jan./jul., 2013. Disponível em: https://rbs.sbsociologia.com.br/index.php/rbs/article/view/23. Acesso em: 20 nov. 2021.

ROLDÃO, Maria do Céu. Formação de professores baseada na investigação e na prática reflexiva. In: PORTUGAL. Ministério da Educação. Direção Geral dos Recursos Humanos da Educação (Org.). Presidência Portuguesa do Conselho da União Europeia: desenvolvimento profissional de professores para a qualidade e para a equidade da aprendizagem ao longo da vida. Lisboa: Ministério da Educação, 2008, p. 40-49. Disponível em: https://crispasuper.files.wordpress.com/2012/06/erc3aanciae28098desenvolvimento-profissional-de-professores-para-a-qualidade-e-para-aequidade-da-aprendizagem-ao-longo-da-vida_3.pdf. Acesso em: 10 dez. 2021.

ROLDÃO, Maria do Céu. Investigação como instrumento da formação profissional de docentes. Formação Docente - Revista Brasileira de Pesquisa sobre Formação de Professores, $1^{\circ}$ de dezembro de 2021 [citado $10^{\circ}$ de dezembro de 2021], v. 13, n. 28, p. 79-90. https://doi.org/10.31639/rbpfp.v13i28.545. Disponível em:

https://revformacaodocente.com.br/index.php/rbpfp/article/view/545

GIMENO SACRISTÁN, José. Consciência e ação sobre a prática como libertação profissional dos professores. In: NÓVOA, António. Profissão professor. 2. ed. Porto: Porto, 1995. p. 63-92.

SHIROMA, Oto Eneida; EVANGELISTA, Olinda. A mística da profissionalização docente. Revista Portuguesa de Educação, v. 16, n. 2, 2003, p. 7-24.disponível em: https://core.ac.uk/download/pdf/25652751.pdf. Acesso em: 10 dez. 2021. 